\title{
Effect of high temperature on early stage of grain filling period in wheat (Triticum aestivum $\mathbf{L}$. )
}

\author{
Chan Seop Ko' ${ }^{1}$, Myung Kyu $\mathrm{Oh}^{2}$, Jong Nae Hyun', Kyeong Hoon Kim², Jin Baek Kim³, \\ Min Jeong Hong, and Yong Weon Seo ${ }^{3 *}$ \\ ${ }^{l}$ Department of Biosystems and Biotechnology, Korea university, Seoul, Korea. \\ ${ }^{2}$ Department of Southern Area Crop Science, NICS, Miryang, Korea \\ ${ }^{3}$ Advanced Radiation Technology Institute, Korea Atomic Energy Research Institute, Jeongeup, Korea

\section{고온이 밀 등숙 초기에 미치는 영향}

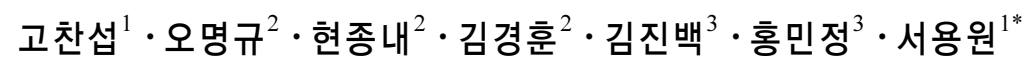 \\ ${ }^{1}$ 고려대학교 생명공학부, ${ }^{2}$ 국립식량과학원 남부작물부, ${ }^{3}$ 한국원자력연구원 첨단방사선연구소
}

\begin{abstract}
Hexaploid wheat (Triticum aestivum L.) exceeds about 30\% of the world's cereal production and cultivated over 220 million ha worldwide. Heat stress during the grain filling period gives detrimental effect on crop yields and has emerged as a serious problem throughout the world. Korean wheat cultivars that were released since 1960s were developed for various aims such as winter hardness, earliness, and pest resistance, etc. However, heat stress resistance is an emerging target for wheat breeding nowadays. Selected 11 Korean wheat cultivars ("Baegjoong", "Dajung", "Goso", "Hanbaek", "Jokyung", "Joeun", "Jopum", "Keumgang", "Olgeuru", "Sinmichal", "Uri") were exposed to high temperature from DAF (days after flowering) 9 13. In this study, plant responses to heat stress as measured by reduction ratios of total chlorophyll contents, 100 seed weight, shoot dry weight can be translated into degree of tolerance. Therefore, these parameters can be used in wheat breeding for heat tolerance during grain filling period. The obtained results allow us to classify cultivars for heat stress tolerance. Pedigree information of Korean cultivars was shown that wheat line of either tolerant, moderate tolerant, or susceptible trait is succeeded to their descendent, which enable breeders to develop heat stress tolerant wheat by appropriate parental choice.
\end{abstract}

Keywords : Wheat, Breeding, Grain-filling stage, Heat stress, Korean cultivars, Pedigree

\section{INTRODUCTION}

Wheat (Triticum aestivum L.) is one of the major grain crops worldwide. Korean wheat cultivars that were developed for various characteristics such as winter hardness, earliness, and pest resistance have been released since 1960s. However, heat stress which was not a significant consideration until 1990 s is increasing problem in wheat production in Korea.

Heat stress is one of the major environmental factors that give a negative impact on crop yields. The increased

\footnotetext{
*Corresponding Author (E-mail: seoag@korea.ac.kr, Tel: +82-2-

3290-3005, Fax: +82-2-3290-3501)
}

(Received on July 17, 2017. Accepted on August 2, 2017.) temperature during reproductive phase of plant growth has emerged as a serious problem all over the world. Constant or transitory high temperatures may affect the plant growth and development which may lead to diverse morphological, physiological and biochemical changes in plants ultimately decrease in yield (Wahid et al. 2007). Heat stress causes inactivation of many thermo-labile proteins (Xue et al. 2011), accumulation of harmful reactive oxygen species in plant cells (Mittler et al. 2012), and in severe cases induces programmed cell death (Grover \& Singh 2013). Temperature directly affects agricultural production, especially crop growth and yield formation. High and extreme temperature events greatly impact on crop yield and quality, particularly during 
the post-heading reproductive stage (Wardlaw \& Moncur 1995).

The optimum temperature to achieve maximum yields of wheat is generally considered to be between $15^{\circ} \mathrm{C}$ and $20^{\circ} \mathrm{C}$ during grain growth (Dupont \& Altenbach 2003). However, wheat is frequently exposed to high temperature during grain filling stage. High temperature is one of the limiting factors affecting wheat production. The elevated temperature often causes grain weight loss and reduces the quality of wheat (Chen et al. 2002, Mullarkey \& Jones 2000, Maestri et al. 2002).

Indeed, the high temperatures during the post-heading stages affect yield (Wardlaw \& Wrigley 1994, Wiegand \& Cuellar 1981) and grain quality of wheat (Stone \& Nicolas 1995), a major crop cultivated worldwide. Plant stress during this stage directly affects grain numbers and grain mass. Since high temperature during grain filling stage is classified as one of the major adversities for wheat, this risk will increase because of the changing climate.

As a significant factor restricting plant growth, heat stress regulates multiple processes in gene expressions in order to globally repress protein synthesis and selectively up regulate stress response proteins. Photosynthesis is the most sensitive physiological process affected by heat stress in plants, so reduction of photosynthesis leads to a reduction in growth and grain yield. Temperatures greater than $30^{\circ} \mathrm{C}$ during grain filling are known to reduce individual kernel mass in wheat (Randall \& Moss 1990, Wardlaw \& Wrigley 1994). When wheat is subjected to heat stress near flowering and grain filling, flowering is 6 7 days faster than non-stressed type, and ripening is also earlier 15 days. Loss of leaf viability during senescence results in a close link between the duration of photosynthetically active leaf area and grain yield in wheat (Simpson 1968, Rawson et al. 1983, Ellen 1987). Leaf senescence is very sensitive to environmental conditions, particularly high temperature (Paulsen 1994). Sustained chlorophyll concentrations during maturation have been used as an efficient indicator of heat tolerance in wheat cultivars (Reynolds et al. 1994). When plants are exposed to high-temperature stress, chlorophyll biosynthesis is inhibited
(Tewari \& Tripathy 1998). Loss of chlorophyll is usually attributed to membrane damage and leaf senescence (Simon \& Ridge 1974, Liu \& Huang 2000, Huang et al. 2003). Therefore, plant's chlorophylls reduction and hastened maturity resulted in grain weight reduction about $45.1 \sim 53.2 \%$ (Al-Khatib \& Paulsen 1990). Genetic approaches leading to improved thermos-tolerance can mitigate the reduction in yield (Hairat \& Khurana 2015).

The purpose of this study is to evaluate varietal responses to heat stress during ripening stage via analyzing phenotypic and agronomic parameters. Total 11 Korean wheat cultivars were evaluated by reduction ratios of total chlorophyll contents, 100 seed weight, and shoot dry weight for their tolerance to high temperature during early stage of grain filling period. In this study, the varietal response to high temperature is also explained by their parental lineage.

\section{MATERIALS \& METHODS}

\section{Plant materials}

Total 11 Korean wheat cultivars ["Goso" (accession no. 102011000188), “Dajung”(102011000789), “Hanbaek”(102 008001304), “Baegjoong”(102008000115), “Jokyung”(1020 05000184), “Sinmichal”(102003000161), “Jopum”(1020020 00523), “Joeun”(102001000044), “Keumgang”(1019980001 91), “Olgeuru"(101998000188), "Uri”(101998000187)] that were released from 1990s to 2010s were incorporated in this study. Seeds of Korean wheat cultivars were kindly provided by the National Institute of Crop Science (NICS), Rural Devel opment Administration (RDA) of Korea.

\section{Plant growth environment}

\section{Vernalization and growth conditions}

Imbibed seeds were set on moisten germination paper (Heavy weight seed germination paper, Anchor Paper Company, Saint Paul, MN, USA) and vernalized at $4{ }^{\circ} \mathrm{C}$ for 6 weeks in a dark chamber. Each seedling was transferred to each pot (Ø top $10 \mathrm{~cm} /$ bottom $8 \mathrm{~cm}$, height $10 \mathrm{~cm}$ ) filled with soil (Sunshine Mix \#1, Sungrow, MA, USA). Plants were grown in well controlled phytotrons (Gaooze control 
system) set $21^{\circ} \mathrm{C} / 19.5^{\circ} \mathrm{C}, 16 \mathrm{~h} / 8 \mathrm{~h}$ (day/night), 65\% 75\% RH. Temperature and relative humidity during the plant growth were measured every 10 minutes by HOBO data loggers (onset computer, UX100-003).

Once the plant reached stage for treatment initiation ( 9 days after flowering), plants that are subjected to heat stress were transferred to another chamber where all conditions are identical to normal phytotron except high temperature. Total 12 plants from each cultivar were transferred into phytotron where temperature set at $32^{\circ} \mathrm{C}$ (Tmax./Tmin.: $34^{\circ} \mathrm{C}$ $131^{\circ} \mathrm{C}$ ) and were subjected to heat stress for 5 days (DAF9 DAF13). Since each cultivar showed different heading date and flowering time, individual plant was labelled for flowing time and transferred to the treatment phytotron at right time of growth stage (DAF9). Pots in the both control and treatment phytotrons were randomly placed and were rotated frequently to avoid positional effects. In order to remove edge effect, the edges of experimental pots were surrounded by extra pots (cv. "Keumgang"). Each plant that was heat treated for 5 days was moved from the treatment phytotron to control phytotron and continues its growth until seed harvest.

\section{Chlorophyll content, seed and dry mass parameters}

Total chlorophyll contents

Total chlorophyll contents were measured by chlorophyll meter (SPAD-502 Plus, FieldScout ${ }^{\circledR}$ meters by using SpecMaps, USA). In order to keep the consistency of measurement, central part of upper side of leaves (flag leaf, $2^{\text {nd }}$ and $3^{\text {rd }}$ leaves from the flag leaf) were measured 3 times at AM 8:00 every day.

Chlorophyll reduction rate (formula shown below) was calculated to measure magnitude of chlorophyll reduction. This parameter could be directly translated to determine the degree of tolerance.

Total chlorophyll reduction ratio $(\%)=$ $\{[$ (chlorophyll content difference between DAF 9 and DAF 12 of Control) - (chlorophyll content difference between
DAF 9 and DAF 12 of Treated)]/(chlorophyll content difference between DAF 9 and DAF 12 of Control) $\} \times$ 100

\section{0 seed weight}

Hundred seed weight and percent reduction in weight per grain weight were measured. As one way to measure plant response to heat stress during grain filling period, a percent reduction in weight per grain number between control and stressed plant (formula is shown below) for each cultivar was scored.

100 seed weight reduction ratio $(\%)=$ $\{[(100$ seed weight of Control $(\mathrm{g}))-(100$ seed weight of Treated $(\mathrm{g}))] /(100$ seed weight of Control $(\mathrm{g}))\} \times 100$

\section{Shoot dry weight}

Above ground plant parts except spikes were harvested and dried at $60^{\circ} \mathrm{C}$ for 24 hours. Shoot dry weight of main stem and $2^{\text {nd }}$ tiller was measured. The magnitude of reduction ratio in response to heat stress was calculated for determining degree of plant tolerance to stress.

Shoot dry weight reduction ratio $(\%)=$

$\{[($ shoot dry weight of control $(\mathrm{g}))$ - (shoot dry weight of treated $(\mathrm{g}))] /($ shoot dry weight of control $(\mathrm{g}))\} \times 100$

\section{Pedigree analysis}

Pedigree information of Korean cultivars was obtained by "RDA, National Institute of Crop Science".

\section{RESULTS}

\section{Plant growth}

The growth of 11 Korean cultivars was observed. Although all cultivars were vernalized same periods (5 weeks), flowering dates which was depicted by days from transplanting to flowering date of 11 cultivars were various. 


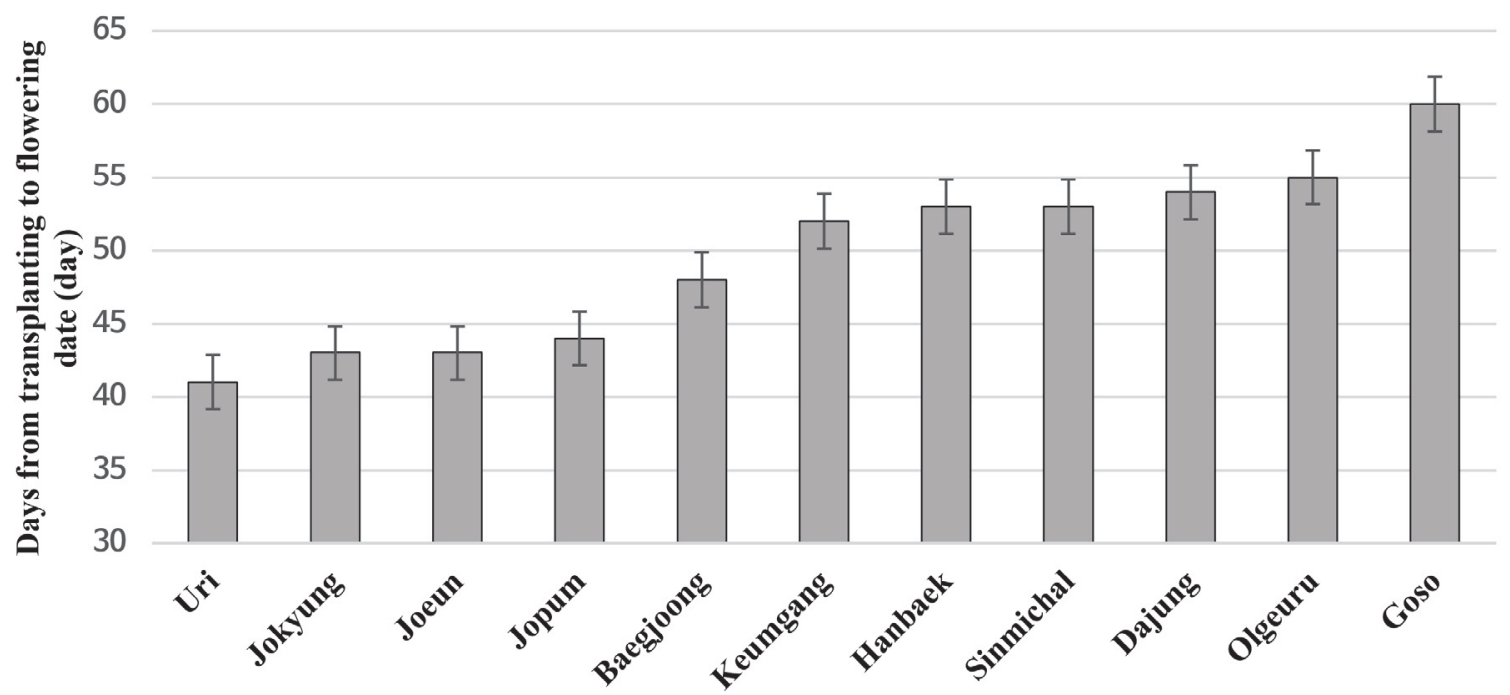

Fig. 1. Days from transplanting to flowering date of 11 Korean cultivars. Y axis shows days from transplanting to flowering date and $\mathrm{x}$ axis indicates Korean cultivars. "Uri" shows the earliest and "Goso" shows the latest heading date.

Among the Korean cultivars, "Goso" was the latest and "Uri" was the earliest with about 20 days flowering date difference (Fig. 1). The maturity data was consistent to the information previously provided by Rural Development Administration (RDA) of Korea (Reference of National Institute of Crop Science). Each plant was tagged for flowering date as well as flowering time and allowed to expose high temperature, which means that treatment was applied to individual plant base.

\section{Total chlorophyll contents}

Total chlorophyll contents of all 11 cultivars were measured for 12 plants per cultivar and 3 times for each plant. Therefore, 36 times measurements were done for each flag leaf, $2^{\text {nd }}$ to flag leaf, and $3^{\text {rd }}$ to flag leaf of each cultivar. Chlorophyll contents of three leaf positions showed a consistence result where flag leaf possessed the highest chlorophyll content and followed by $2^{\text {nd }}$ to flag leaf and $3^{\text {rd }}$ to flag leaf. Regardless of whether the plants were under either control or treated, this phenomenon was same (Fig. 2).

Total chlorophyll contents of treated plants were drastically decreased as high temperature treatment time lapse. There was significant difference of total chlorophyll contents between control and treated plants as well as among the treatment duration for all cultivars (Fig. 2).

Total chlorophyll reduction ratios at 3 different leaves (flag leaf, $2^{\text {nd }}$ and $3^{\text {rd }}$ to flag leaf) for all 11 cultivars were shown in Fig. 3.

Referred to chlorophyll content reduction ratios, 4 cultivars ("Sinmichal", "Hanbaek", "Olgeuru", "Dajung") showed susceptible in all 3 leaves to heat stress during DAF9 to DAF12. Other 5 cultivars ("Baegjoong”, "Jokyung”, "Uri”, "Keumgang", "Jopum") also showed susceptible at $3^{\text {rd }}$ leaves, but flag and $2^{\text {nd }}$ to flag leaf did not show critical reduction ratios. Finally, "Joeun", "Goso", showed the least descent reduction rate in response to high temperature. It was difficult to discriminate between control and treatment with bare eyes for these cultivars. Total chlorophyll reduction ratio of third to flag leaf of all 11 cultivars was always senescence critically.

In case of "Goso" which was the latest cultivar showed less vigor than other cultivars throughout its growth. Because of this retard physiological phenomenon, it would be hard to determine whether the chlorophyll reduction ratio was representing degree of stress or endowed physiological defect.

Although each cultivar showed difference response to heat stress, we were able to divide them into 3 groups where tolerant, moderate tolerant, and susceptible cultivars. 

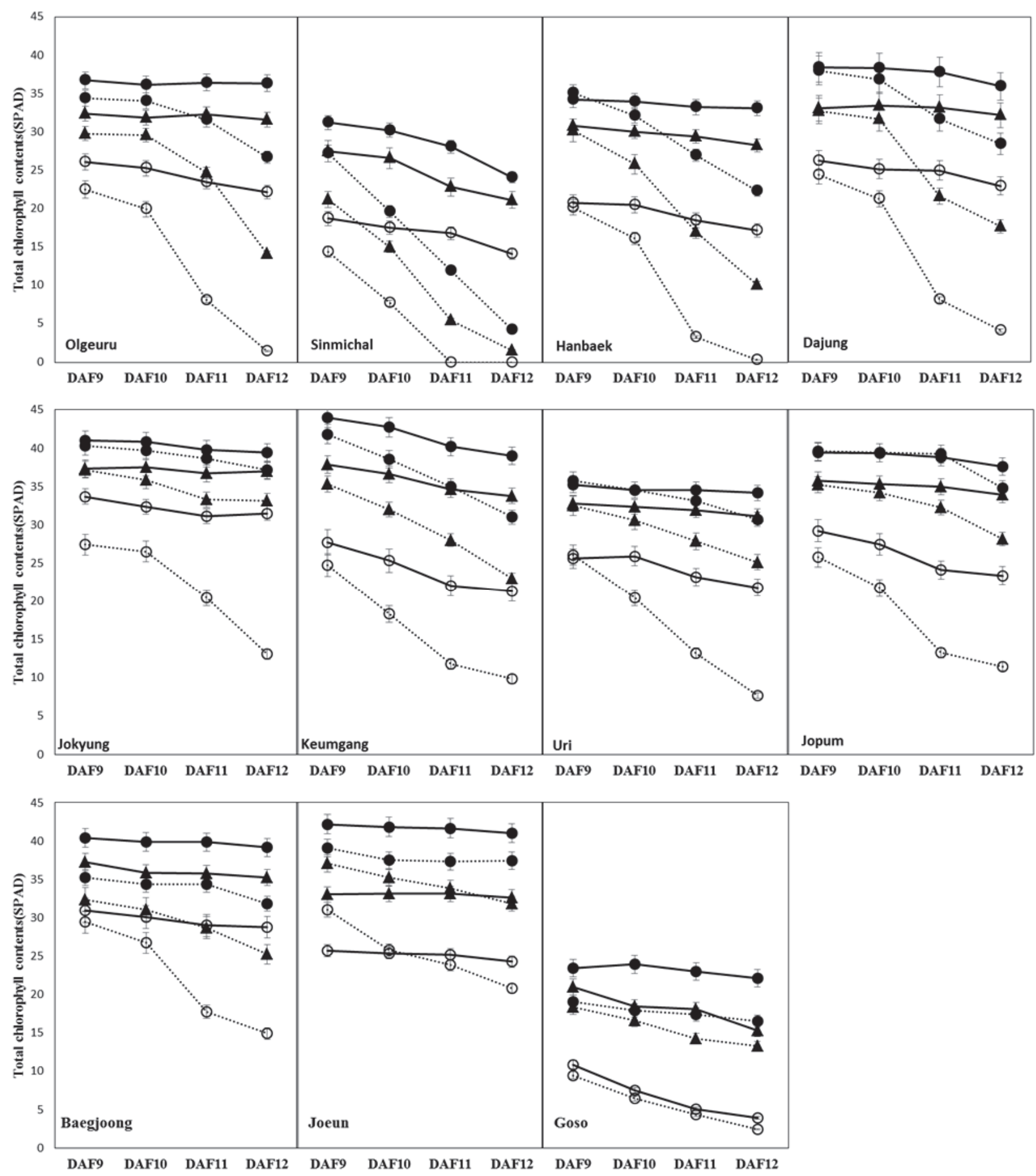

Fig. 2. Total chlorophyll contents of 11 Korean cultivars between DAF9 to DAF12. Solid, triangle, open circle represent flag leaf, $2^{\text {nd }}$ and $3^{\text {rd }}$ to flag leaf, respectively. Solid line shows control environment and dotted line indicates heat treated environment. $\mathrm{X}$ axis shows time lapse from DAF9 to DAF12. Y axis indicates total chlorophyll contents (SPAD). 


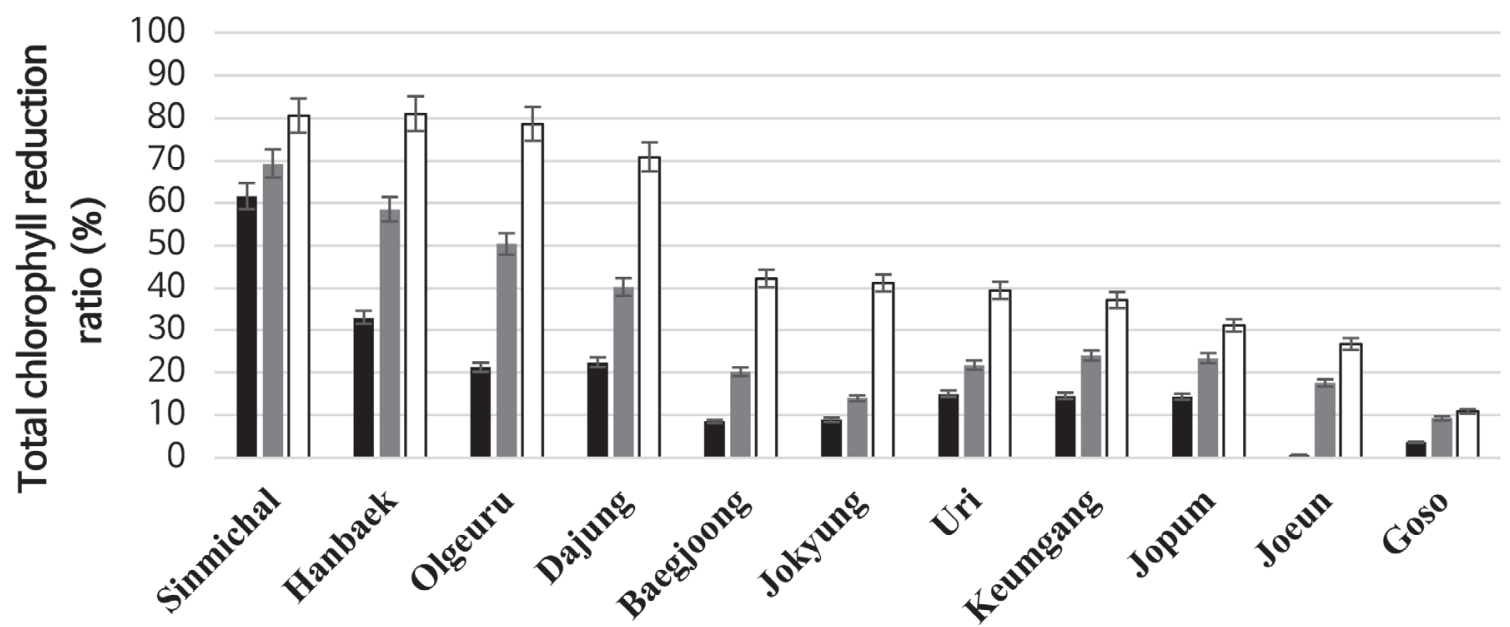

Fig. 3. Chlorophyll content reduction ratio of 11 Korean cultivars. Black, gray, white box indicate flag leaf, $2^{\text {nd }}$ and $3^{\text {rd }}$ to flag leaf, respectively. The cultivars ("Sinmichal", "Hanbaek", "Olgeuru", "Dajung") showed high reduction ratio not only in flag leaf (exceed $20 \%$ ), and $2^{\text {nd }}$ to flag leaf (exceed $40 \%$ ) but also $3^{\text {rd }}$ to flag leaf (exceed $70 \%$ ). Cultivars "Baegjoong", "Jokyung", "Uri", "Keumgang", and "Jopum" could be grouped moderate tolerance to heat stress, followed by remaining cultivars "Joeun" and "Goso".

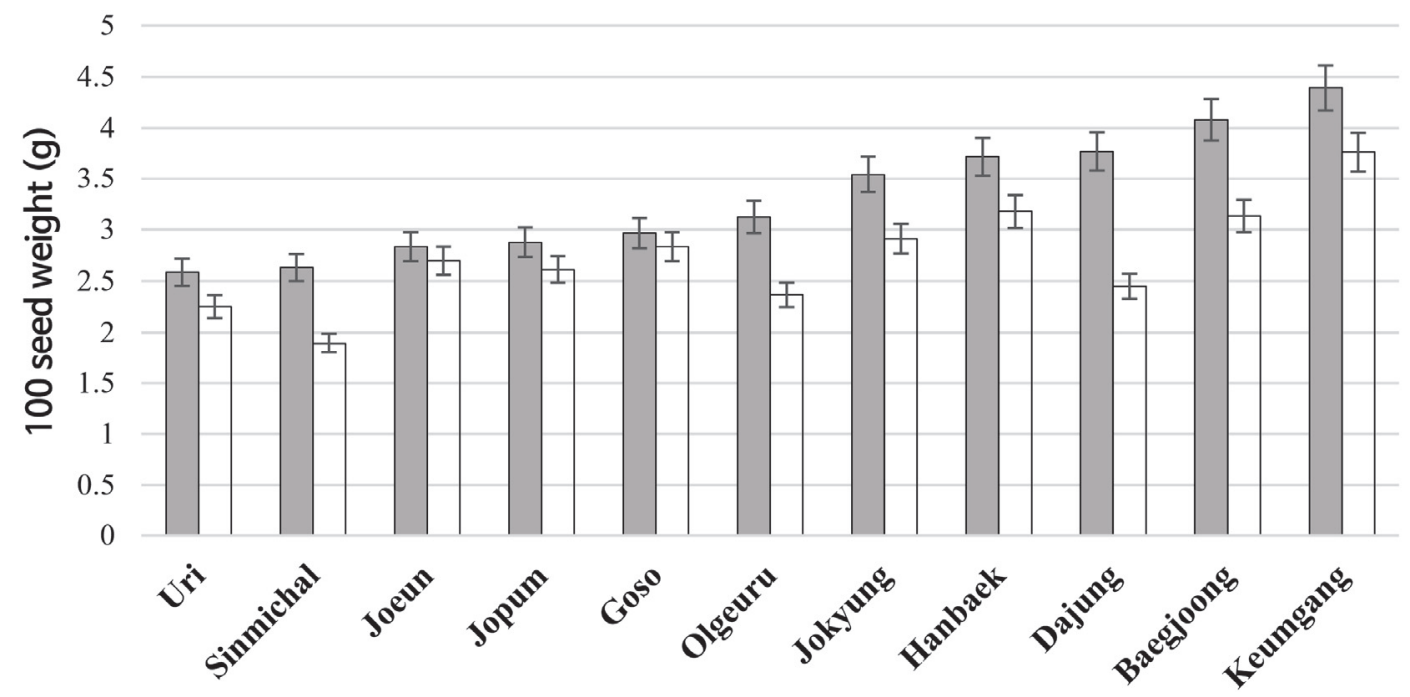

Fig. 4. Hundred seed weight of 11 Korean cultivars. Gray bar shows 100 seed weight at control environment and blank bar shows at high temperature treated environment. $\mathrm{X}$ axis is name of Korean cultivars and $\mathrm{y}$ axis is 100 seed weight (g).

\section{0 seed weight}

Differences of 100 seed weight among all 11 Koean cultivars in conrol and treated were found. The most widely planted cultivar "Keumgang" showed the highest 100 seed weight followed by recent release high yielding cultivar "Baegjoong" (Fig. 4) The varietal performance for this trait was genetically fixed and showed significant difference between cultivars. Therefore, evaluation of 100 seed weight among treated cultivars might not enough to provide plant tolerance to heat stress.

Therefore, the magnitude of reduction ratio of grain weight that was ascribed by heat stress could be a diagnostic tool for plant tolerance to stress. Korean wheat cultivars showed different grain weight reduction ratios with wide ranges of differences (Fig. 5).

The cultivars showed the magnitude of reduction ratio 


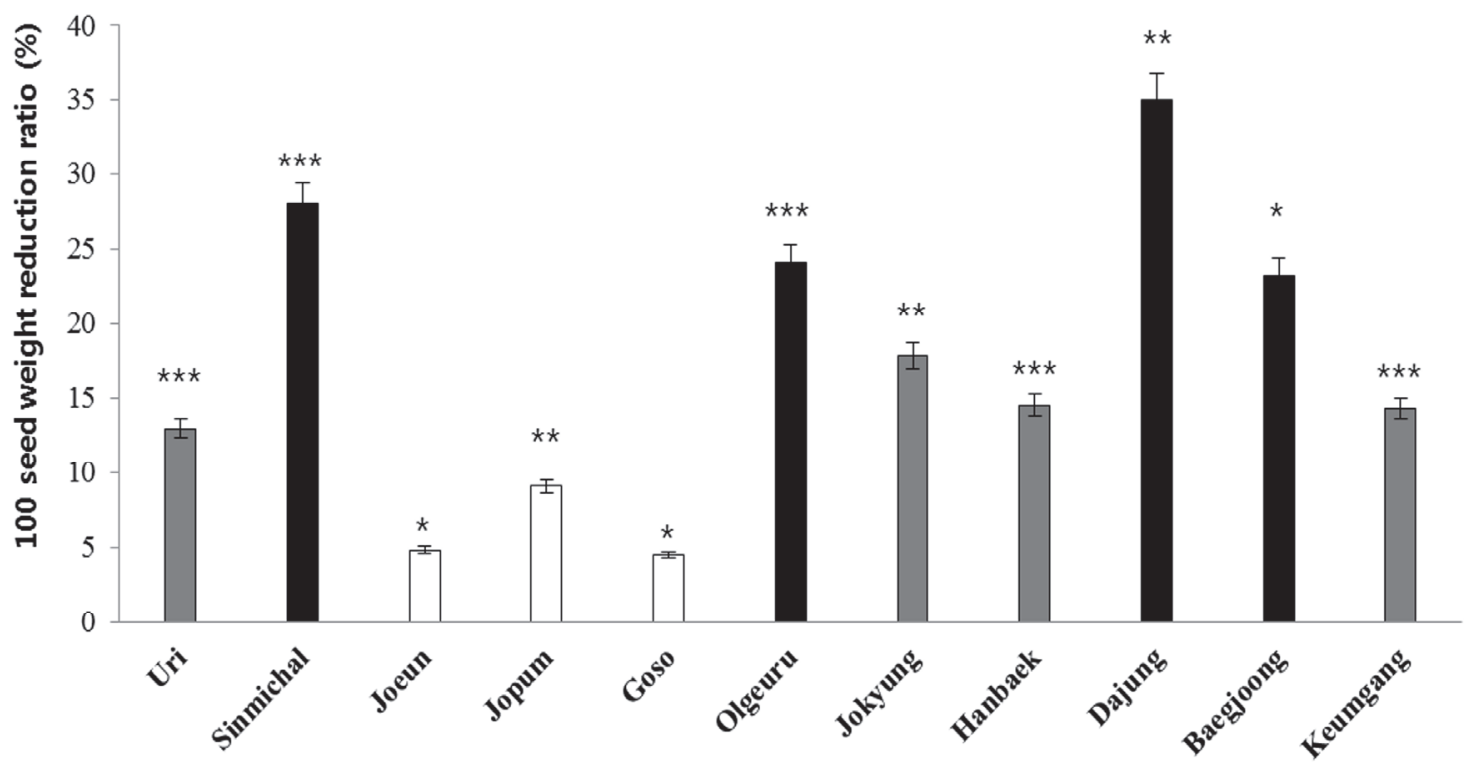

Fig. 5. Reduction ratio of 100 seed weight between control and treated cultivars. $\mathrm{X}$ axis indicates cultivars and $\mathrm{Y}$ axis shows reduction ratio of 100 seed weight. Black bars ("Dajung", Olgeuru", "Baegjoong", "Sinmichal") is considered as susceptible, gray bars ("Jokyung", "Hanbaek", "Keumgang", "Uri") can be moderate tolerance, and white bars ("Jopum", "Joeun", "Goso") shows critical tolerance on high temperature (under 5\%). The significant difference between control and treated cultivars was analyzed $(0.01>* * *, 0.05>* *, 0.1>*)$.

exceeding $20 \%$ could be considered as susceptible to heat stress. "Dajung" showed the highest ratio (34.8\%) followed by "Olgeuru" (31.8\%), "Baegjoong" (23.9\%) and "Sinmichal" (21.1\%). Cultivars "Jokyung", "Hanbaek", Keumgang", "Uri" showed $10 \% \sim 15 \%$ of reduction ratios for 100 seed weight between control and treated seeds. These cultivars could be considered as moderate tolerance to heat stress. Likewise, cultivars ("Jopum", "Joeun", "Goso") could be belonged to tolerant cultivars because they showed less than $10 \%$ reduction ratios.

\section{Shoot dry weight}

Plant biomass was mainly heritable trait and was also affected by numerous environmental factors such as plant density, soil fertility, and other limiting factors. Dry weight of shoot part except spike was measured for control and treated plants.

"Baegjoong" showed more than $33.04 \%$ reduction ratio of shoot dry weight and "Goso" showed least reduction ratio $(2.49 \%)$.

Korean wheat cultivars could be grouped by degree of tolerance to heat stress as measured by reduction ratio of shoot dry weight, where tolerant cultivars were "Joeun", "Uri", "Jopum", "Goso" and moderate tolerant cultivars were "Sinmichal", "Hanbaek", "Keumgang". Cultivars "Baegjoong", "Dajung", “Olgeuru", “Jokyung”, which showed least tolerance to heat stress during grain filling period could be considered susceptible.

The result showed that all cultivars experienced high temperature stress and responded differently (Fig. 6). In association with total chlorophyll reduction ratio, the severity of shoot dry weight reduction ratio showed similar result. Sensitive cultivars in chlorophyll parameter showed more than $20 \%$ reduction ratio and tolerance cultivars showed less than $10 \%$ (Fig. 6).

Cultivar grouping for heat tolerance during grain filling period

All three parameters were considered to classify Korean wheat cultivar for its tolerance to heat stress during early stage of grain filling period. Korean wheat cultivars could be divided into at least 3 groups based on magnitude of 
40

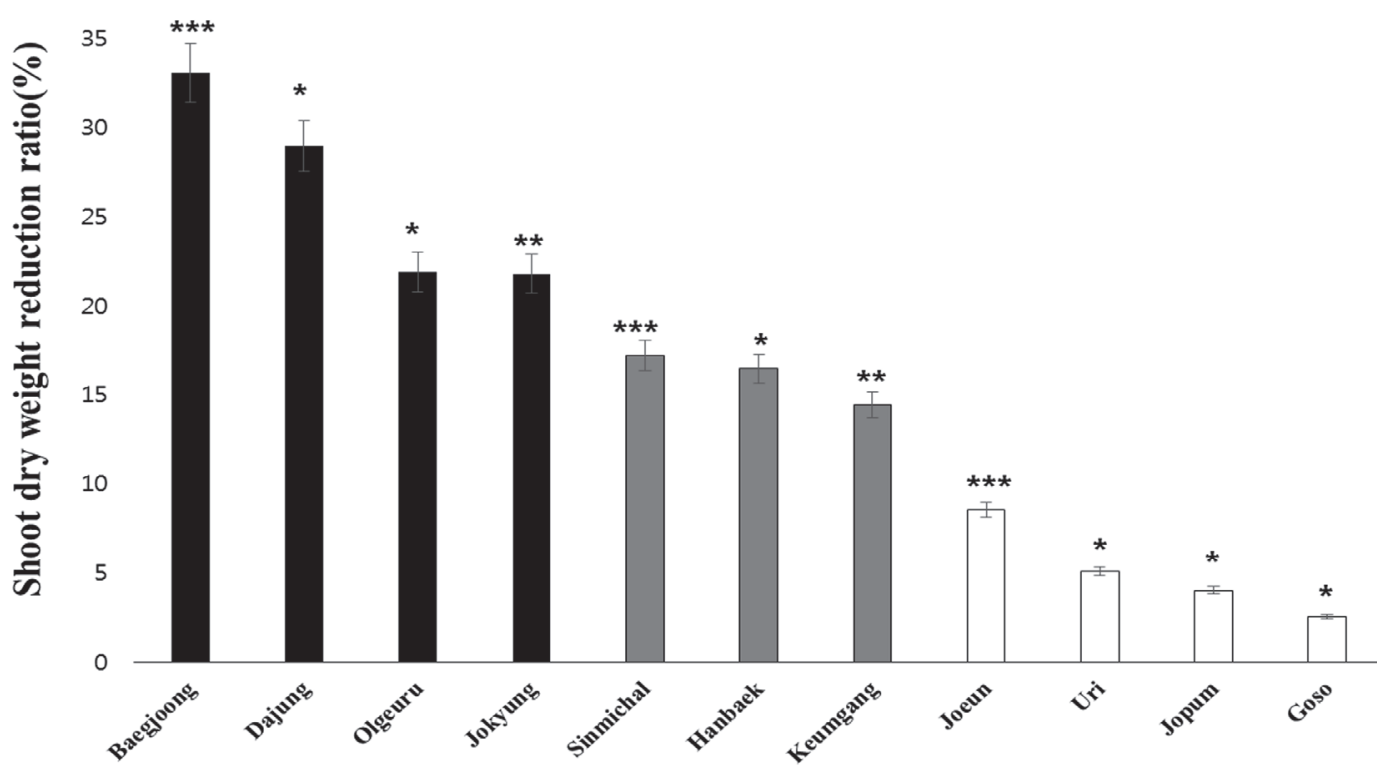

Fig. 6. Shoot dry weight reduction ratio of 11 Korean cultivars. Cultivars can be grouped as susceptible (dark black bar), moderate tolerance (gray bar), and tolerance (white bar) to heat stress during early stage of ripening period. The significant difference between control and treated cultivars was analyzed $(0.01>* * *, 0.05>* *, 0.1>*)$.

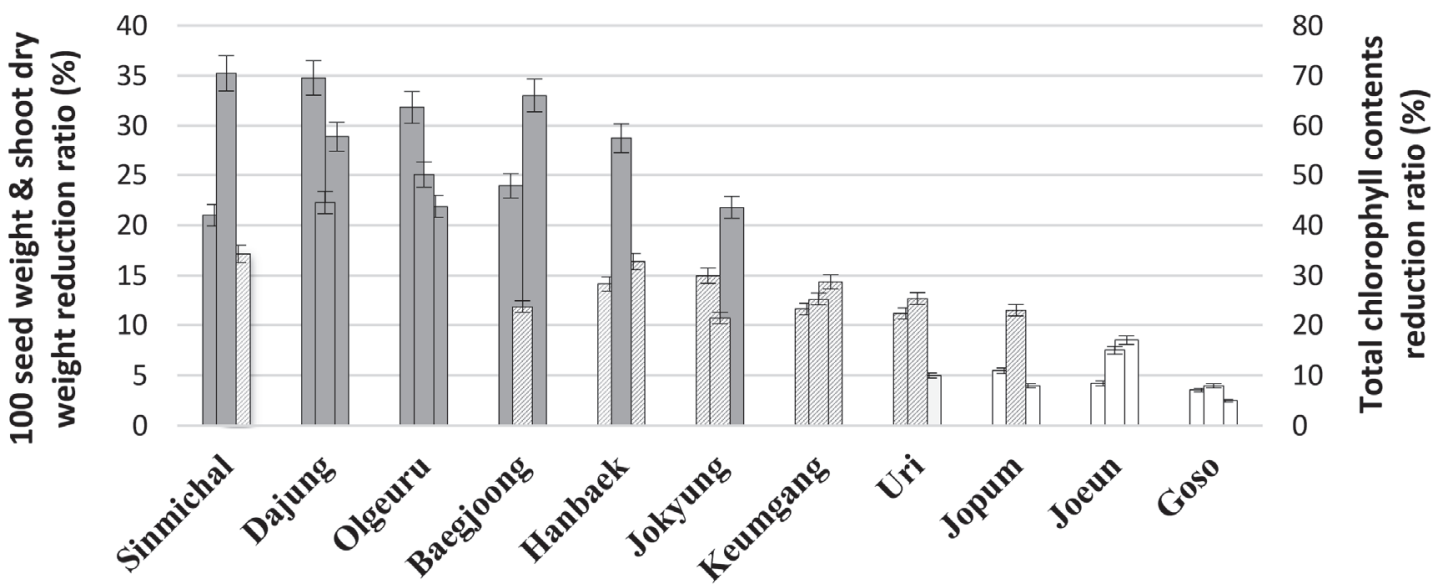

Fig. 7. All 3 parameters (reduction ratio of total chlorophyll contents, 100 seed weight, shoot dry weight) were combined together to determine varietal response to heat stress during early stage of grain filling period. Varietal responses are depicted in 3 bars per each variety [left: ratio of 100 seed weight reduction (\%), middle: ratio of chlorophyll content reduction (\%), right: ratio of shoot dry weight reduction (\%)]. Tolerance as indicated by each parameter is marked in 3 different levels of darkness (dark bar: susceptible, gray bar: moderate tolerance, blank bar: tolerance). Cultivars are in ordered by least tolerance (left) to tolerance (right).

deleterious effect on total chlorophyll contents, 100 seed weight, and shoot dry weight. Although the range of decreased magnitudes were various among the parameters within the cultivar, the combined results of all 3 parameters showed consistency in general (Fig. 7). Based on the magnitude of all 3 parameters combined, "Dajung", "Olgeuru", "Sinmichal" and "Baegjoong" that showed significant high reduction in 2 or 3 parameters could be considered as susceptible cultivars. "Hanbaek", "Jokyung", "Uri" and "Keumgang" that showed moderate reduction in 2-3 parameters were considered as 


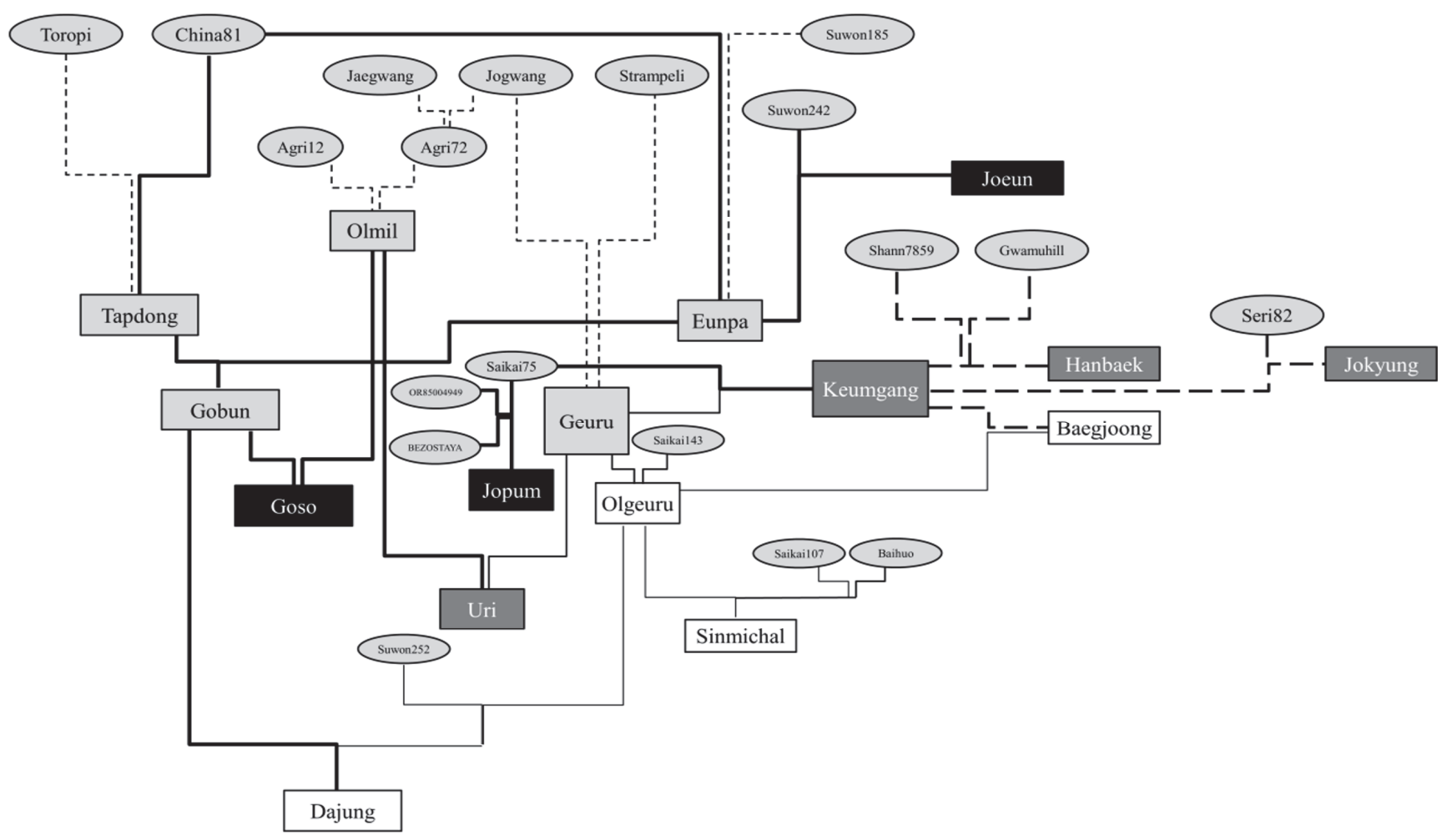

Fig. 8. Pedigree of Korean wheat cultivars. Total 11 Korean cultivars are indicated in square boxes, where dark boxes indicate tolerant cultivars, gray boxes indicate moderate tolerance, and blank boxes indicate susceptible cultivars. Breeding lines are indicated by gray-circles and gray-squares. The different degree of tolerance paths are depicted by thick solid line (tolerance path), thick dotted line (moderate tolerance), and solid line (susceptible). Dotted line indicates lines that are not included in this study.

moderate tolerance. "Jopum", "Joeun", "Goso" that showed relatively less reduction ratio could be considered as heat tolerance.

\section{Parental inheritance of heat stress tolerance}

Heat stress tolerance lineage of Korean wheat cultivars in related to pedigree was illustrated in Fig. 8. The different varietal response to heat tolerance could be expected by parental information.

"Olgeuru" was obtained by cross between "Geuru" and "Saikai 143". When "Geuru" (susceptible) was crossed with resistant cultivars like "Olmil" or "Saikai 75" the progenies ("Uri", "Keumgang") showed moderate tolerance. In this experiment, "Dajung" showed an exception of interpretation of appropriate relationship between pedigree and tolerance because one of its parents "Gobun" is assumed to be tolerance.
However, this could be explained by relatively strong influence of susceptible trait of "Olgeuru" to next generation. "Sinmichal" which was obtained by the cross between "Olgeuru" and one of $F_{2}$ lines ("Sakai107"/"Baihuo") showed susceptible. The susceptibility of "Sinmichal" might be derived from "Olgeuru". The susceptible trait of "Baegjoong" could also be pathed from "Olgeuru".

We could expect that "Saikai 75" was tolerant cultivar because the moderate tolerance of "Keumgang" that was obtained by cross between "Saikai 75" and "Geuru" which was susceptible. Therefore, the resistance of "Jopum" should be inherited by one of the parents, "Saikai 75 ". The moderate tolerance of "Jokyung" and "Hanbaek" could be expected to be pathed from "Keumgang" because "Keumgang" was used as one of their parents. The moderate tolerance of "Uri" indicated that "Olmil" would be a tolerant cultivar because the susceptible "Geuru" is one of the parents. The tolerance 
of "Olmil" could be pathed to the "Goso" which was confirmed as resistance.

Resistance "Joeun" had been developed by cross between "Eunpa" and "Suwon 242". "Eunpa" affected two cultivars "Joeun" and "Gobun". "Joeun" showed tolerance to heat stress and Gobun's progeny line "Goso" also possessed tolerant trait. Therefore, Eunpa's tolerance to high temperature during grain filling period should be inherited to succeeding progenies.

\section{DISCUSSION}

Fall planted Korean wheats undergo freezing winter and are regrowth next spring followed by transition to double ridge stage. They flower on late April and grain filling is normally ceased on late May or early June. Heat stress at grain filling period gives a detrimental effect on yield as well as end-use quality. Plants exposed to heat stress during grain filling period stops growing and speed up seed maturation incompletely and leaf senescence critically. Therefore, understanding wheat response to high temperature during reproductive stage especially, early stage of grain-filling period is very important for design wheat breeding strategies for enhanced yielding.

In this paper, the mode of plant response to high temperature during early stage of grain filling period using 11 Korean wheat cultivars were analyzed. The agronomic traits for each cultivar are similar to the information provided by National Institute of Crop Science (RDA).

Photosynthesis is the most sensitive physiological process to elevated temperature (Wahid et al. 2007) and any reduction in photosynthesis affects growth and grain yield of wheat (Al-Khatib \& Paulsen 1990). Heat stress reduces photosynthesis through disruptions in the structure and reductions in total chlorophyll content (Xu et al. 1995). In addition, chlorophyll biosynthesis is inhibited under exposure to heat stress $42^{\circ} \mathrm{C}$ (Tewari \& Tripathy 1998), which hastens leaf senescence that proceeds away from the spike. Therefore, the degree of leaf senescence can be one of the appropriate parameters to measure stress severity and plant response to stress.
Chlorophyll reduction ratios for susceptible cultivars showed a sharp decrease all measured leaves (flag leaf, $2^{\text {nd }} \& 3^{\text {rd }}$ to flag leaf). Especially "Sinmichal" showed high reduction ratio level in all 3 leaves and "Joeun" showed least reduction ratio of total chlorophyll contents. Although the reduction ratio of total chlorophyll contents at three different leaves of each plant showed a consistence result, some cultivars showed little different response based on leaf positions. "Baegjoong", "Jokyung", "Keumgang", "Uri" and "Jopum" were showed susceptible reduction ratios only in $3^{\text {rd }}$ to flag leaf and showed negligible reduction ratio for flag leaf and $2^{\text {nd }}$ to flag leaf. "Joeun" and "Goso" showed the least reduction ratio in response to high temperature. "Joeun" kept green color throughout the treatment and is noticeably different to other cultivars. "Goso" showed the latest heading date and the least germination rate among the 11 cultivars. The retarded growth and less vigorous during the life span in both control and treatment might hinder to obtain right reduction ratio. Although "Goso" was included in tolerance group, it could be easily removed in the breeding program because of unfavorite growth.

Heat stress speeds up development of the spike (Porter \& Gawith 1999) where reducing spikelet number and thus, the weight of grains per spike (Saini \& Aspinall 1982). Reduced grain weight ( $\sim 1.5 \mathrm{mg}$ per day) can occur for every $1{ }^{\circ} \mathrm{C}$ above $15-20^{\circ} \mathrm{C}$ (Streck 2005). Therefore, magnitude of reduction in 100 seed weight which was ascribed by stress could be translated into plant resistance to stress. One of the measurements of heat stress during ripening period could be grain weight. As agronomic parameters 100 or 1000 seed weight could be used both to measure production and grain quality. This grain characteristic was normally fixed by process of cultivar development. For example, "Uri" showed the least weight and "Keumgang" showed the heaviest. Since 100 or 1000 seed weight might not suitable to measure plant tolerance to stress, we used the reduction ratio of 100 seed weight between control and treatment. Susceptible 3 cultivars ("Dajung", “Olgeuru", "Baegjoong”) showed high 100 seed weight in non-treated environment, but their decreased level was large enough to determine as susceptible. Although 
"Sinmichal" showed relatively low 100 seed weight among susceptible cultivars and low magnitude of reduction in treatment, its reduction ratio (22\%) is enough to belong susceptible. As moderate tolerance cultivars, "Hanbaek", "Jokyung", "Keumgang", and "Uri" showed reduction ratio between 11 and 15\%. Although "Hanbaek" shows large reduction ratio in total chlorophyll contents, the intermediate magnitude reduction ratio (14\%) in 100 seed weight resulted in moderate tolerance. "Joeun" and "Goso" showed little change between control and treatment, same as those of the previous experiment. The results of 100 seed weight reduction ratio for 11 Korean cultivars were almost similar to those of total chlorophyll contents because these 2 parameters were crucial indicates of plant responses to adverse environment.

Plant responses to high temperature as measured by reduction ratios of total chlorophyll content, 100 seed weight, and shoot dry weight provided criteria for plant tolerance to stress. Although all cultivars were stressed by high temperature, the differences of parameters between control and treatment were not always big or small for tolerance or susceptible, respectively. However, we were able to determine and group the varieties for their tolerance with all 3 parameters was combined. Therefore, these differences could be applied to wheat breeding program for selection of heat stress tolerant line.

Expansion of genetic variability in the wheat gene pool is important for breeding programs aimed to improve heat tolerance during reproductive and grain-filling stages. Although several reports indicate the existence of genetic diversity for heat tolerance in conventional wheat varieties (Wardlaw \& Wrigley 1994, Fokar et al. 1998, Savin et al. 1999, Gibson \& Paulsen 1999, Spiertz et al. 2006), new sources of genetic diversity must be explored. One option is to cross-breed wheat (Triticum aestivum) which was known its tolerant/susceptible ability. Parental choice should be the most important factors in cross breeding. Therefore, knowledge of parental information before making crosses is crucial for success of breeding. We were able to find that varietal tolerance/susceptibility to heat stress during early stage of grain filling period could be inherited to succeeding generation. We also found that the magnitude of varietal contribution to hybrid $F_{1}$ is different among varieties. Wheat cultivar "Olgeuru" which was susceptible to heat stress influences its susceptibility to next generation $\left(F_{1}\right)$ relatively high. All cultivars that have "Olgeuru" as one of their parents were considered to be susceptible to heat stress. "Dajung" showed an exception of interpretation of appropriate relationship between pedigree and tolerance because one of the parents "Gobun" was assumed to be tolerance. However, this could be explained by relatively strong influence of susceptible trait of "Olgeuru" to next generation.

Since limited numbers of cultivars were tested, the portion of parental contribution in terms of tolerance/susceptibility might not be clearly explained. However, the progeny showed the traits which were inherited from their parents.

High temperature stress during plant growth is considered seriously nowadays. Furthermore, heat stress during reproductive stage is a critical detrimental factor resulted in yield reduction as well as poor quality. Since high temperature during grain filling period is now considered as a major interference on yield potential, we expect that obtained results allow us to classify cultivars for heat stress tolerance.

Pedigree information of Korean cultivars are showed that wheat lines provide either tolerance, moderate tolerant or susceptible trait to their descendent, which enable breeders to develop heat stress tolerance wheat by appropriate parental choice.

\section{ACKNOWLEDGEMENT}

This work was carried out with the support of " $R \& D$ agenda Agriculture \& Technology development program (Project No. PJ0122732017)" Rural Development Administration, Republic of Korea.

\section{REFERENCES}

1. Alkhatib K, Paulsen GM. 1990. Photosynthesis and productivity during high-temperature stress of wheat genotypes from major world regions. Crop Sci. 30: 
$1127-1132$.

2. Chen $\mathrm{X}$, Moore $\mathrm{M}$, Milus EA, Long DL, Line RF, Marshall D, Jackson L. 2002. Wheat stripe rust epidemics and races of Puccinia striiformis f. sp. tritici in the United States in 2000. Plant Dis. 86: 39-46.

3. Dupont FM, Altenbach SB. 2003. Molecular and biochemical impacts of environmental factors on wheat grain development and protein synthesis. J. Cereal Sci. 38: 133-146.

4. Ellen J. 1987. Effects of plant density and nitrogen fertilization in winter wheat (Triticum aestivum L.) I. Production pattern and grain yield. Neth. J. Agr. Sci. 35: 155-162.

5. Fokar M, Nguyen HT, Blum A. 1998. Heat tolerance in spring wheat. I. Estimating cellular thermotolerance and its heritability. Euphytica 104: 1-8.

6. Gibson L, Paulsen G. 1999. Yield components of wheat grown under high temperature stress during reproductive growth. Crop Sci. 39: 1841-1846.

7. Grover D, Singh J. 2013. Post-harvest losses in wheat crop in punjab: Past and Present. Agr. Econ. Review 26: 293-297.

8. Hairat S, Khurana P. 2015. Improving photosynthetic responses during recovery from heat treatments with brassinosteroid and calcium chloride in Indian bread wheat cultivars. Am. J. Plant Sci. 6: 1827-1849.

9. Huang L, Brooks SA, Li W, Fellers JP, Trick HN, Gill BS. 2003. Map-based cloning of leaf rust resistance gene Lr21 from the large and polyploid genome of bread wheat. Genet. 164: 655-664.

10. Liu X, Huang B. 2000. Heat stress injury in relation to membrane lipid peroxidation in creeping bentgrass. Crop Sci. 40: 503-510.

11. Maestri E, Klueva N, Perrotta C, Gulli M, Nguyen HT, Marmiroli N. 2002. Molecular genetics of heat tolerance and heat shock proteins in cereals. Plant Mol. Biol. 48: 667-681.

12. Mittler R, Finka A, Goloubinoff P. 2012. How do plants feel the heat? Trends Biochem. Sci. 37: 118-125.

13. Mullarkey M, Jones P. 2000. Isolation and analysis of thermotolerant mutants of wheat. J. Exp. Bot. 51: 139-146.

14. Paulsen GM. 1994. High temperature responses of crop plants. Phy. Det. Of Crop Yield 365-389.

15. Porter JR, Gawith M. 1999. Temperatures and the growth and development of wheat: a review. Eur. J. Agron. 10: 23-36.

16. Randall P, Moss H. 1990. Some effects of temperature regime during grain filling on wheat quality. Aust. J. Agr. Resour. Ec. 41: 603-617.

17. Rawson H, Hindmarsh J, Fischer R, Stockman Y. 1983. Changes in leaf photosynthesis with plant ontogeny and relationships with yield per ear in wheat cultivars and 120 progeny. Funct. Plant Biol. 10: 503-514.

18. Reynolds M, Balota M, Delgado M, Amani I, Fischer R. 1994. Physiological and morphological traits associated with spring wheat yield under hot, irrigated conditions. Funct. Plant Biol. 21: 717-730.

19. Saini H, Aspinall D. 1982. Abnormal sporogenesis in wheat (Triticum aestivum L.) induced by short periods of high temperature. Ann. Bot-London 49: 835-846.

20. Savin R, Calderini DF, Slafer GA, Abeledo LG. 1999. Final grain weight in wheat as affected by short periods of high temperature during pre- and post-anthesis under field conditions. Funct. Plant Biol. 26: 453-458.

21. Simon A, Ridge E. 1974. The use of ampicillin in a simplified selective medium for the isolation of fluorescent pseudomonads. J. Appl. Microbiol. 37: 459-460.

22. Simpson G. 1968. Association between grain yield per plant and photosynthetic area above the flag-leaf node in wheat. Can. J. Plant Sci. 48: 253-260.

23. Spiertz J, Hamer R, Xu H, Primo-martin C, Don C, van der Putten P. 2006. Heat stress in wheat (Triticum aestivum L.): effects on grain growth and quality traits. Eur. J. Agron. 25: 89-95.

24. Stone P, Nicolas M. 1995. A survey of the effects of high temperature during grain filling on yield and quality of 75 wheat cultivars. Aust. J. Agr. Resource 46: 475-492.

25. Streck NA. 2005. Climate change and agroecosystems: the effect of elevated atmospheric $\mathrm{CO}_{2}$ and temperature on crop growth, development, and yield. Cienc. Rural 35: 730-740.

26. Tewari AK, Triphthy BC. 1998. Temperature-stress-induced impairment of chlorophyll biosynthetic reactions in cucumber and wheat. Plant Physiol. 117: 851-858.

27. Wahid A, Gelani S, Ashraf M, Foolad MR. 2007. Heat tolerance in plants: an overview. Environ. Exp. Bot. 61: 199-223.

28. Wardlaw I, Moncur L. 1995. The response of wheat to high temperature following anthesis: The rate and 
duration of kernel filling. Funct. Plant Biol. 22: 391-397.

29. Wardlaw I, Wrigley C. 1994. Heat tolerance in temperate cereals: an overview. Funct. Plant Biol. 21: 695-703.

30. Wiegand C, Cuellar J. 1981. Duration of grain filling and kernel weight of wheat as affected by temparature. Crop Sci. 21: 95-101.

31. Xu Q, Paulsen AQ, Guikema JA, Paulsen GM. 1995.
Functional and ultrastructural injury to photosynthesis in wheat by high temperature during maturation. Environ. Exp. Bot. 35: 43-54.

32. Xue GP, Kooiker M, Drenth J, Mcintyre CL. 2011. TaMYB13 is a transcriptional activator of fructosyltransferase genes involved in $\beta-2,6$-linked fructan synthesis in wheat. Plant J. 68: 857-870. 